\title{
Central Hemodynamics for Management of Arteriosclerotic Diseases
}

\author{
Junichiro Hashimoto
}

Medical Center, Miyagi University of Education, Sendai, Japan

Arteriosclerosis, particularly aortosclerosis, is the most critical risk factor associated with cardiovascular, cerebrovascular, and renal diseases. The pulsatile hemodynamics in the central aorta consists of blood pressure, flow, and stiffness and substantially differs from the peripheral hemodynamics in muscular arteries. Arteriosclerotic changes with age appear earlier in the elastic aorta, and age-dependent increases in central pulse pressure are more marked than those apparent from brachial pressure measurement. Central pressure can be affected by lifestyle habits, metabolic disorders, and endocrine and inflammatory diseases in a manner different from brachial pressure. Central pulse pressure widening due to aortic stiffening increases left ventricular afterload in systole and reduces coronary artery flow in diastole, predisposing aortosclerotic patients to myocardial hypertrophy and ischemia. The widened pulse pressure is also transmitted deep into low-impedance organs such as the brain and kidney, causing microvascular damage responsible for lacunar stroke and albuminuria. In addition, aortic stiffening increases aortic blood flow reversal, which can lead to retrograde embolic stroke and renal function deterioration. Central pressure has been shown to predict cardiovascular events in most previous studies and potentially serves as a surrogate marker for intervention. Quantitative and comprehensive evaluation of central hemodynamics is now available through various noninvasive pressure/flow measurement modalities. This review will focus on the clinical usefulness and mechanistic rationale of central hemodynamic measurements for cardiovascular risk management.

Key words: Arteriosclerosis, Aorta, Stiffness, Blood pressure, Blood flow

\section{Introduction: Historical View}

Arterial blood pressure (BP) has long been recognized as an important biomarker of arterial function. More than 280 years ago, Stephen Hales compared the arterial system to a fire extinguisher with an air chamber (the so-called "Windkessel"), showing that the pulse waveform of BP (e.g., systolic upstroke and diastolic exponential decay) depends on aortic distensibility ${ }^{1}$. Until the invention of the brachial cuff ausculatory method by Riva-Rocci and Korotkoff, the BP waveform had been utilized to diagnose hypertension with arterial degeneration ${ }^{2}$. In the early 20 th century, it was realized that the pulsatile BP wave is transmitted along the arterial tree from the central aorta to

Address for correspondence: Junichiro Hashimoto, Medical Center, Miyagi University of Education, 149 Aoba, Aramaki, Aoba-ku, Sendai 980-0845, Japan

E-mail: hashimoto@med.tohoku.ac.jp

Received: March 30, 2017

Accepted for publication: April 24, 2017 peripheral arteries at a speed depending on arterial stiffness ${ }^{3)}$. In the mid-20th century, the reflection phenomenon of BP waves was recognized by experimental studies involving frequency domain analysis of aortic impedance ${ }^{4,5)}$. Human (invasive) studies involving time domain analysis of the intra-aortic BP waveform also confirmed that it is largely explicable by the transmission and reflection phenomena and closely associated with aortic wall stiffness ${ }^{6,7)}$. Clinical introduction of applanation tonometry for noninvasive BP recording revealed age-dependent (i.e., arteriosclerosisinduced) changes in the radial and carotid artery waveforms, leading to the proposal of the concept of the augmentation index $(\mathrm{AIx})^{8)}$. A mathematical transformation method has also been devised to generate aortic waveforms from radial waveforms and to estimate aortic $\mathrm{BP}^{\text {9) }}$.

Similar to BP measurement, blood flow measurement has progressed from invasive intra-arterial recordings (e.g., through an electromagnetic flowmeter) to noninvasive duplex ultrasound or MRI record- 
ings, which enable us to evaluate pulsatile hemodynamics in the central aorta more easily and comprehensively. With the increasing availability of these new pressure/flow measurement modalities, more attention has recently been paid to the clinical significance of central hemodynamics in cardiovascular diseases (CVDs). This review will summarize the current evidence on the potential for central hemodynamic indices to stratify cardiovascular risk and/or serve as a surrogate marker of clinical endpoints. This review will also focus on the pathophysiological mechanisms underlying the link between central hemodynamic abnormalities and end-organ damage/dysfunction and discuss future directions of clinical research.

\section{What is Central BP?}

Central BP is generally defined as BP in the ascending aorta. In a broader sense, it can refer to $\mathrm{BP}$ in the thoracic or abdominal aorta, representing BP exerted at the level of the heart, brain, and kidney ${ }^{10}$. Due to the phenomenon of pulse pressure (PP) amplification ${ }^{11)}$, the central (systolic and pulse) pressures essentially differ from the brachial pressures. The central-brachial BP difference considerably varies among individuals ${ }^{12)}$; for instance, there is an approximate difference of $<5 \mathrm{mmHg}$ in some people (e.g., elderly people with a very stiff aorta), whereas it occasionally exceeds $30 \mathrm{mmHg}$ in others (e.g., young people with a distensible aorta ${ }^{13)}$ or during exercise ${ }^{14)}$ ). This difference cannot be estimated directly from conventional cuff BP measurement alone (i.e., solely from the two extremes of brachial BPs), but it can be actually estimated by adding information on the BP pulse waveform (see "How is central BP measured?" below).

The BP pulse waveform can be explained on the basis of the wave transmission and reflection phenomena along the arterial tree. In cardiac systole, the blood ejected from the left ventricle generates an incident (forward) BP wave. The incident wave then travels antegradely from the central aorta to the peripheral arteries at a speed termed "pulse wave velocity (PWV)." When the incident wave encounters highimpedance sites (e.g., high-resistance arterioles and arterial bifurcations), it is reflected and then travels retrogradely toward the central aorta at a speed similar to PWV. PWV is high (normally around 5-10 m/s) enough for the pulse to return up to the central aorta within the same cardiac cycle so that the reflected wave interferes with the incident wave to augment BP. The degree of augmentation is generally evaluated as AIx, which is the ratio of augmented pressure to PP (Fig. ${ }^{15)}$ ).

\section{How is Central BP Measured?}

Until a quarter-century ago, aortic BP was only available in an invasive manner by inserting an intraarterial catheter-tip manometer or a fluid-filled catheter connected to a pressure transducer. Noninvasive estimation of aortic BP has become feasible since the technological development of applanation tonometry ${ }^{16,17)}$ performed on arteries running near the body surface (such as the carotid and radial arteries) ${ }^{8)}$ and mathematical transformation of tonometric BP waveforms ${ }^{9}{ }^{18)}$. Applanation (flattening) of arteries can be manually performed using a pencil-type probe (i.e., tonometer) or (semi)automatically performed using a hands-free tonometric system. To date, there are three major methods available for central BP estimation.

\section{1) Estimation from Carotid BP Waveform}

This method is based on the premise that the carotid waveform is deemed to be identical to the aortic waveform ${ }^{19)}$. The carotid waveform is usually recorded with applanation tonometry and then calibrated by the brachial cuff pressures [i.e., by the mean arterial pressure (MAP) and diastolic BP] to derive absolute values of central BP. The rationale for calibration by brachial BPs is the observation that MAP and diastolic BP are almost constant in the elastic and conduit arteries (e.g., between the central aorta and brachial artery) ${ }^{20)}$. MAP is either calculated directly from the area under the curve of the brachial (or radial) pulse waveform or estimated indirectly from an equation such as $\mathrm{MAP}=$ diastolic $\mathrm{BP}+0.4 \times \mathrm{PP}^{21)}$. This method has the advantage of not requiring any mathematical waveform transformation to estimate absolute central BP values. Nevertheless, it may be technically difficult in some cases to record (flatten) the carotid waveforms appropriately or reproducibly because of the anatomical characteristics of the carotid artery surrounded by soft tissues. The carotid pulse wave recordings can occasionally be affected by respiratory variation. Carotid AIx correlates well with invasively determined aortic AIx, although the former is reported to be half of the latter ${ }^{19)}$.

\section{2) Mathematical Conversion from Radial to Central BP Waveform with Transfer Function}

In this method, the radial waveform is recorded with applanation tonometry and then converted to the corresponding aortic waveform using a frequency domain transfer function. There are two types of transfer function: generalized ${ }^{9,18)}$ and individualized. The former is commercially available and more widely used. Though still debated ${ }^{22)}$, a generalized transfer function is considered valid for normal subjects, for 


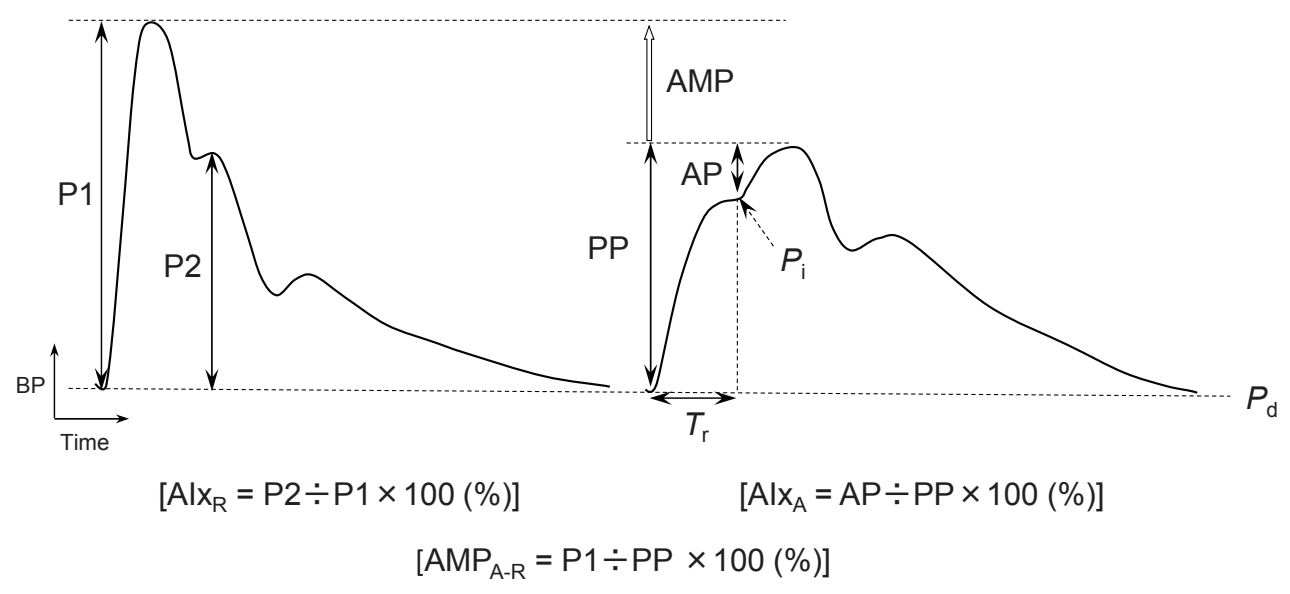

Fig. 1. Pressure pulse waveforms of radial artery (A) and central aorta (B)

AIxA indicates aortic augmentation index; AIxr, radial augmentation index; AMP, pulse pressure amplification; $\mathrm{AMP}_{\mathrm{A}-\mathrm{R}}$, aorta-to-radial AMP ratio; AP, augmented pressure; BP, blood pressure; P1, early systolic peak pressure; P2, late systolic peak pressure; $P_{\mathrm{d}}$, diastolic pressure; $P_{\mathrm{i}}$, pressure at inflection point; PP, pulse pressure; and $T_{\mathrm{r}}$, round-trip travel time. Reproduced from Hashimoto ${ }^{15}$.

patients with various diseases ${ }^{18,23,24)}$, during exercise $^{25)}$, during pharmacological intervention ${ }^{26)}$, and during the Valsalva maneuver ${ }^{18)}$. The synthesized aortic waveform is normally calibrated with brachial diastolic BP and MAP to obtain central BP; MAP is calculated from the area under the radial waveform on the basis that the radial and brachial waveforms are deemed to be identical ${ }^{8)}$. Aortic BP estimated using this method somewhat underestimates systolic BP and overestimates diastolic BP as measured directly using an invasive method ${ }^{27)}$, but these errors almost entirely depend on the inaccurate calibration by the brachial cuff measurement ${ }^{28)}$. The estimated aortic BP closely correlates with invasive aortic $\mathrm{BP}^{29)}$. Reproducibility has been repeatedly verified in terms of aortic BP and AIx estimation ${ }^{30-32)}$.

\section{3) Direct Estimation from Radial BP Waveform without Using Transfer Function}

It is empirically recognized that aortic systolic (maximum) BP is equal to the late systolic (second) peak (or "shoulder") of radial BP ${ }^{33)}$. Based on this recognition, the radial waveform is calibrated with brachial systolic and diastolic BPs to determine radial late systolic BP, which corresponds to aortic systolic BP. Although this method cannot generate the aortic waveform itself, it can offer the advantage of directly estimating aortic systolic BP and PP without applying a complicated waveform transformation. Radial AIx is usually calculated as the ratio of late systolic to early systolic BP peak amplitude (Fig. 1) ${ }^{34)}$. This method has been validated using invasive studies ${ }^{35,36)}$, and the estimated radial AIx and late systolic pressure are reported to be reproducible ${ }^{37)}$. Though only rare $(<$ $5 \%$ ), aortic BP may be unavailable because of an undetectable radial second peak (e.g., under conditions of marked tachycardia or vasodilation).

In addition, several devices have been newly developed and are currently available for noninvasive central BP recordings. Some of them adopt brachial cuff-based pulse volume plethysmography in place of applanation tonometry ${ }^{38-41)}$; therefore, they are portable and capable of measuring ambulatory 24-h central BP. The N-point moving average method has also been proposed for the estimation of the aortic BP peak from the radial BP waveform ${ }^{42)}$. These novel methodologies can provide more detailed information on central BP (e.g., circadian variation); further validation studies are required for general use in terms of accuracy, reproducibility, and prognostic significance.

\section{Factors Affecting Central BP}

\section{1) Age (Arteriosclerosis)}

Age is the most potent accelerating factor associated with arteriosclerosis, and it strongly influences aortic BP waveforms (Table 1). With advancing age, elastic fibers in the aortic medial layer gradually undergo degeneration and are replaced with stiffer collagenous fibers, and the resultant decrease in the 
Table 1. Comparisons of aortic pulse waveform characteristics between subjects with and without aortosclerosis

\begin{tabular}{lcc}
\hline Aortosclerosis & $(-)$ & $(+)$ \\
\hline Aortic pressure waveform $^{*}$ & & \\
& & \\
& Low & High \\
Incident pressure wave & Narrow & Wide \\
Augmented pressure & Slow & Fast \\
Pulse pressure & Long & Short \\
Pulse wave velocity & Normal & Figh \\
Round-trip travel time & Slow & Small \\
Augmentation index & Large & \\
Diastolic pressure decay & & \\
Pulse pressure amplification &
\end{tabular}

*Arrows indicate the arrival of reflected waves.

medial elastin/collagen ratio causes progressive stiffening of the aortic wall and reduction in aortic compliance ${ }^{43}$, 44). Such a pathological process is usually referred to as arteriosclerosis. Hypertension accelerates this process because of the fatiguing effects of excessive cyclic stress on elastic fibers ${ }^{43)}$. Aortic stiffening increases aortic PWV and shortens the return time of the reflected BP wave and thus increases the augmented pressure. Moreover, as aortic distensibility decreases with age, systolic upstroke and diastolic decay of aortic BP become steeper. All these changes are responsible for a marked widening of aortic PP with age (Table 1). It should be noted here that compared with central elastic arteries, peripheral muscular arteries undergo little arteriosclerotic change ${ }^{45)}$; therefore, age-dependent PP change is more remarkable in the former ${ }^{46}$.

Epidemiological studies have shown progressive linear increases in aortic augmented pressure and reflected wave magnitude with age ${ }^{47,48)}$. Aortic AIx increases until the sixth decade but reaches a plateau or even decreases thereafter ${ }^{47,49)}$, probably because both the numerator (augmented pressure) and denominator (PP) increase linearly with age but with different intercepts on the pressure axis ${ }^{50)}$.

\section{2) Gender and Height}

In general, women show a higher AIx than men ${ }^{51)}$. This is mainly attributed to their difference in body height ${ }^{52)}$, which relates to the path length between the central aorta and peripheral reflecting sites and thus determines the timing of wave reflection. However, the association between gender and AIx can be observed even independently of body height, suggesting an intrinsic gender difference in arterial function ${ }^{53)}$. Given a higher AIx in women, gender difference in aortic PP is less obvious than that in brachial $\mathrm{PP}^{54)}$.

\section{3) Heart Rate and Ejection Duration}

AIx increases as the heart rate decreases ${ }^{55)}$. This is because a longer ejection duration resulting from a lower heart rate causes a wider incident wave to overlap with a reflected wave, with the round-trip travel time of these two waves being little affected by the heart rate. It can also be a reason why nonvasodilating beta-blocker administration increases $\mathrm{AIx}^{56)}$.

\section{4) Lifestyle (Smoking, Alcohol, Caffeine, and Sodium Intake)}

Smoking of cigarettes or cigars increases aortic AIx and PWV acutely and chronically ${ }^{57,58)}$. Chronic smokers had a higher aortic (but a similar brachial) systolic BP than nonsmokers ${ }^{57)}$. Smoking-induced AIx increase correlates with the change in the plasma cotinine level ${ }^{59)}$. Even short-term smoking cessation reduces $\mathrm{AIx}^{60)}$.

Alcohol intake has divergent effects on AIx; acute ingestion reduces aortic systolic $\mathrm{BP}$ and $\mathrm{AIx}$, while chronic excessive consumption elevates these in men ${ }^{61)}$. The effect of chronic alcohol consumption on aortic BP may differ by gender; heavier alcohol intake is associated with a higher AIx in healthy young men $^{62)}$ but not in postmenopausal women ${ }^{63)}$.

Caffeine affects peripheral wave reflection to elevate aortic BP to a greater extent than that apparent from brachial $\mathrm{BP}^{64)}$. Caffeinated but not decaffeinated coffee ingestion raises aortic AIx and PWV ${ }^{65)}$. Black 
and green tea can also elevate $\mathrm{AIx}^{66)}$. The combination of smoking and caffeine intake produces a synergistic detrimental effect on aortic PWV and $\mathrm{AIx}^{67)}$.

Excessive sodium intake increases aortic stiffness and wave reflection, while sodium restriction improves them effectively ${ }^{68,69)}$.

\section{5) Diabetes, Hypercholesterolemia, and Obesity}

Inconsistent results have been reported with regard to AIx in diabetes. Pediatric patients with type 1 diabetes are reported to have an increased aortic $\mathrm{AIx}^{70)}$, while adult patients with type 2 diabetes can have an increased ${ }^{71)}$, normal ${ }^{72)}$, or even reduced ${ }^{73)} \mathrm{AIx}$ despite widened PP. The mechanism underlying these apparently conflicting observations is still debated, but some patients with type 2 diabetes may have compensatory hyperinsulinemia (in response to insulin resistance), which could induce peripheral vasodilation and diminish wave reflection, even with a stiffened aorta. It may also involve central (abdominal) obesity, which is known to reduce $\mathrm{AIx}^{73)}$. Aortic $\mathrm{AIx}$ in patients with hypercholesterolemia is reported to be higher $\operatorname{than}^{74)}$ or similar to ${ }^{75)}$ that in subjects with normocholesterolemia. Metabolic syndrome may not be associated with AIx in treated hypertension ${ }^{76)}$. Taking these reports together, metabolic disorders can have inconsistent effects on AIx and thus peripheral wave reflection, in contrast to a relatively consistent (increasing) effect on PWV and arterial stiffness ${ }^{77}$. It should be of note, however, that aortic BP elevation can often be observed in these disorders even without any increase in wave reflection, namely through an increase in the incident wave height.

Arterial stiffness and wave reflection may be influenced not only by glucose or lipid metabolism but also by mineral metabolism abnormalities. For instance, higher serum phosphorus levels are shown to be associated with increases in PWV and AIx even among the general population with normal kidney function ${ }^{78)}$.

\section{6) Other Related Diseases}

An elevation in AIx is observed in hypothyroidism $^{79)}$ and hyperparathyroidism ${ }^{80)}$, both of which represent the endocrine disorders considered responsible for hypertension. In obstructive sleep apnea syndrome, aortic (but not peripheral) BP and AIx can be elevated, particularly in the early morning ${ }^{81)}$. Aortic BP may decrease in response to nasal continuous positive airway pressure treatment even without parallel changes in peripheral $\mathrm{BP}^{82)}$. In patients with Kawasaki disease who develop coronary artery lesions, wave reflection indices are elevated and the aortic waveforms resemble those observed in the elderly ${ }^{83)}$. Primary inflammatory diseases, including rheumatoid arthritis, may be independently associated with increased central BP and $\mathrm{AIx}^{84)}$, although it remains controversial whether systemic inflammation in primary hypertension and chronic kidney disease (CKD) is a cause or consequence of aortic stiffness ${ }^{85}$. Systemic sclerosis, which often involves microvascular lesions, is associated with enhanced peripheral wave reflection despite normal aortic stiffness ${ }^{86}$. Sickle cell disease with the hemoglobin SS genotype is associated with lower arterial stiffness and wave reflections owing to higher nitric oxide availability ${ }^{87)}$.

\section{Is Central BP Useful for Risk Stratification of CVD?}

\section{1) Prospective Studies}

So far, a number of prospective observational cohort studies have been conducted to investigate the predictive ability of central BP indices for CVD events. The results are summarized in Table $\mathbf{2}^{88-106)}$ and have been discussed elsewhere in our previous review ${ }^{107)}$. These study cohorts can be classified according to the underlying diseases, e.g., patients with renal disease, patients with coronary heart disease, and the general population. As a whole, most (but not all) of currently available data indicate that central BP indices (such as central PP, AIx, and PP amplification) can predict CVD events more precisely than and/or independently of brachial BP, particularly in high-risk populations (Table 2; for more details, please refer to the previous review ${ }^{107)}$ ).

\section{2) Cut-Off Value}

The definition of the cut-off values for central $\mathrm{BP}$ has not yet been established. While the normal upper limits of brachial (casual) BP are usually defined as $140 / 90 \mathrm{mmHg}$, it is difficult to set corresponding thresholds for central BP because of the PP amplification, which considerably varies among individuals according to age and BP levels ${ }^{12}$. Based on a distribution approach from an epidemiological cross-sectional database, brachial BP values of 140/90 $\mathrm{mmHg}$ correspond to central BP values of $\sim 125 / 90 \mathrm{mmHg}^{108)}$. Based on a prognostic outcome-driven approach from a prospective database, central $\mathrm{BP}$ of $130 / 90 \mathrm{mmHg}$ has been proposed as a diagnostic threshold value ${ }^{109)}$. Clearly, the validity of these cut-off values needs to be confirmed by further investigation.

\section{Does Central BP Serve as a Surrogate Marker for Intervention?}

Brachial BP has long been recognized as a useful marker for the management of CVD as well as hyper- 
Table 2. Prospective observational studies on predictive value of central blood pressure parameters for cardiovascular events

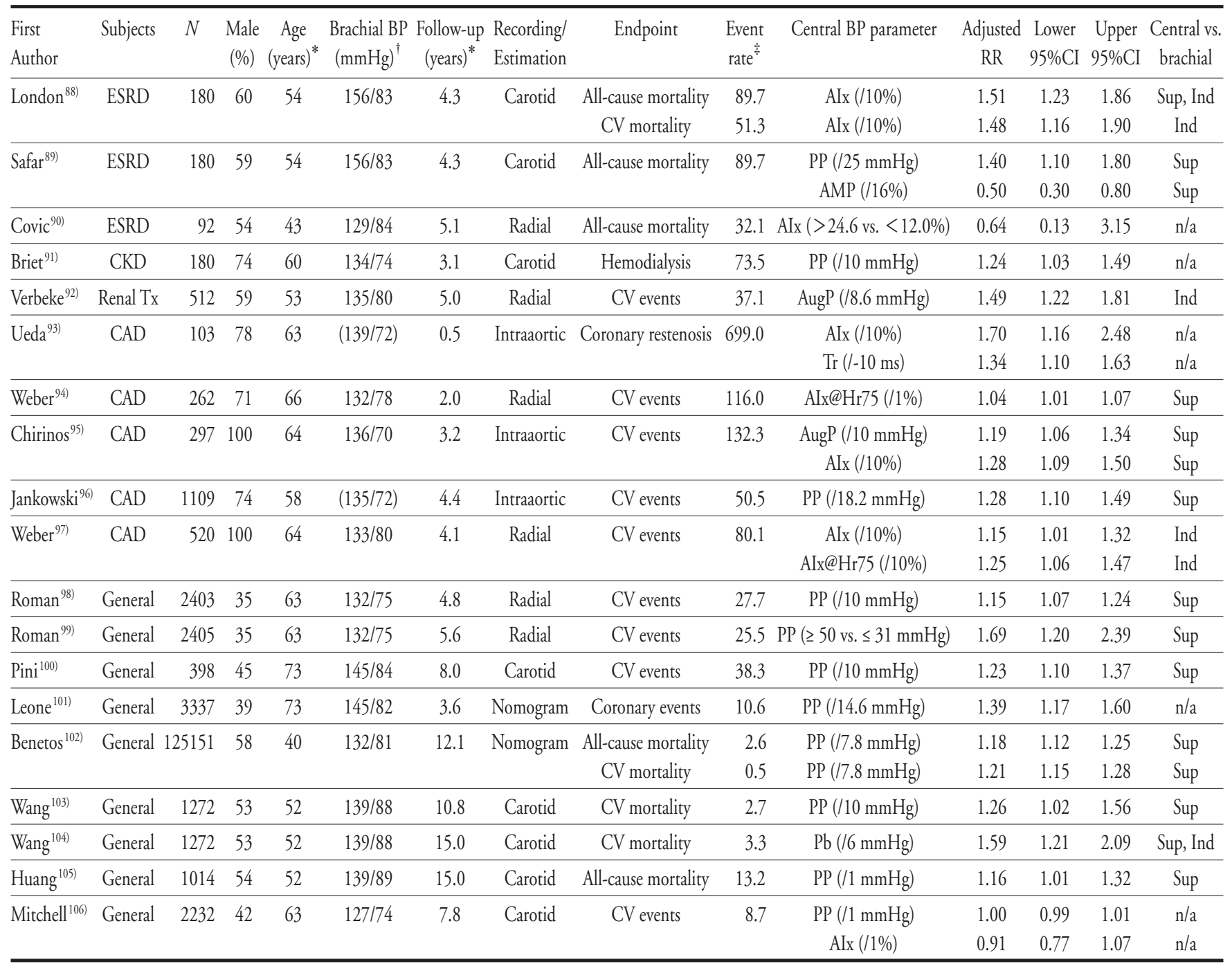

AIx: augmentation index; AIx@Hr75: AIx adjusted for heart rate of 75 bpm; AMP: pulse amplification; AugP: augmented pressure; BP: blood pressure; CAD: coronary artery disease (or suspect); CI: confidence interval; CKD: chronic kidney disease; CV: cardiovascular; ESRD: end-stage renal disease; Ind: predictive independency of central BP parameters from brachial BP; n/a: data not available; Pb: reflected wave amplitude; PP: pulse pressure; RR: relative risk; Sup: predictive superiority of central BP parameters over brachial BP; Tr: travel time; Tx: transplantation. * Mean or median. ${ }^{\dagger}$ Except for aortic BP in parentheses. ${ }^{\$}$ Per 1000 person-year (by estimate). Reproduced from Hashimoto et al. ${ }^{107)}$.

tension. For introducing central BP measurement into routine clinical practice, the most critical issue is to determine whether central BP is superior to brachial $\mathrm{BP}$ in evaluating therapeutic effects and predicting their consequences.

It is known that nitroglycerine has a stronger hypotensive effect on central BP than that apparent from brachial BP measurement ${ }^{110}$. This is attributable to a reduction in wave reflection resulting from the peripheral vasodilating action of nitroglycerine. The opposite effects are observed for nonvasodilating $\beta$ -blockers, which lower central BP to a lesser extent than brachial $\mathrm{BP}^{111)}$. So far, different effects of various antihypertensive drug classes on central BP have been demonstrated by several randomized multicenter clinical trials. For instance, the CAFÉ substudy ${ }^{56}$ of the ASCOT trial ${ }^{112}$ ) showed that individuals assigned to the amlodipine/perindopril group had a $4.3 \mathrm{mmHg}$ lower central systolic BP than those assigned to the atenolol/thiazide group, despite a similar brachial BP. The EXPLOR study ${ }^{113}$ demonstrated that an amlodipine/valsartan combination decreases central BP and AIx more effectively than an amlodipine/atenolol combination. In addition, the PARAMETER study has recently shown that sacubitril/valsartan (LCZ696), an angiotensin receptor neprilysin inhibitor, is more 
potent than olmesartan in reducing central $\mathrm{BP}^{114)}$.

Central BP can serve as a therapeutic surrogate marker for the prevention of major CVD events. Data from the abovementioned CAFÉ study indicate that the modest intergroup difference in central BP, which is undetectable by conventional brachial BP measurement, contributed to the better cardiovascular outcome in the amlodipine group observed in the ASCOT study ${ }^{112)}$. In addition, compared with brachial BP, central BP can better predict the regression of target organ damage (e.g., left ventricular hypertrophy ${ }^{15)}$ and carotid artery wall hypertrophy ${ }^{116)}$ ) during antihypertensive treatment. Such regression, which likely results from vasolidator-induced reduction in peripheral wave reflection ${ }^{117,}{ }^{118)}$, could be closely linked to a reduction in CVD events. These lines of evidence suggest a potential benefit of central BPguided antihypertensive therapy for CVD management.

At present, only limited data are available regarding the therapeutic impact of medication other than antihypertensive drugs (e.g., statin and antidiabetic drugs). In the CAFE-LLA substudy ${ }^{119)}$, atorvastatin therapy sufficient to reduce CVD events in the ASCOT trial ${ }^{122}$ had no influence on central BP or AIx. In contrast, in a placebo-controlled study ${ }^{120)}$, atorvastatin but not the placebo induced significant reductions in central BP, AIx and PWV. Linagliptin (a dipeptidyl peptidase-4 inhibitor) did not affect central $\mathrm{BP}$ and AIx in a placebo-controlled study of patients with diabetes ${ }^{121)}$. Metformin (but not the placebo) reduces central BP and AIx in patients with nonalcoholic fatty liver disease ${ }^{122)}$ and in young women with polycystic ovary syndrome ${ }^{123)}$. Tetrahydrobiopterin, a nitric oxide synthase cofactor, can lower central AIx but not PWV in patients with $\mathrm{CKD}^{124)}$. Anti-inflammatory treatment may reduce PWV and/or AIx in some patients with primary inflammatory disorders ${ }^{125)}$. Obviously, further investigation is required.

\section{Pathophysiological Relations of Central Hemodynamics to Arteriosclerotic Diseases: Hypothetical View and Future Directions}

As the central aorta stiffens, peripheral endorgans undergo progressive degeneration in the vascular structure and gradual deterioration in the physiological function, which can lead eventually to the sudden occurrence of symptomatic CVD. There is substantial evidence showing that aortic PWV predicts major cardiovascular events, including myocardial infarction, heart failure, stroke, and renal failure ${ }^{126,127)}$. Until quite recently, however, relatively little was known about the underlying mechanisms by which aortic stiffening causes target organ damage or dysfunction. Results of the latest studies indicate that the central hemodynamics, including aortic BP and flow, plays a pivotal role in the causal mechanisms.

Aortic pulsatile flow is an important constituent of central hemodynamics. The flow waveform differs from the pressure waveform and greatly varies among different aortic sites ${ }^{128)}$. According to previous studies based on Doppler ultrasound, the flow waveform in the proximal descending aorta is biphasic (to-and-fro) comprising systolic forward and diastolic reverse components, and the reverse/forward flow ratio linearly increases with aortic stiffening ${ }^{129)}$. Such an increase in aortic flow reversal could alter the blood flow distribution to various organs and thus directly relate to the pathophysiological mechanisms of arteriosclerotic CVD (see below). The bidirectional (i.e., antegrade and retrograde) nature of aortic flow seems quite intriguing from a physiological view, given its potential relevance to aortic BP composed of the two waves going in opposite directions (i.e., forward and reflected waves). The PP amplification (i.e., pressure gradient) and aortic/peripheral PWV ratio (i.e., stiffness gradient) also seem to be significant determinants of pulsatile flow production ${ }^{130-132)}$.

\section{1) Stroke}

Cerebrovascular disease can be broadly divided into two categories: microvascular and macrovascular stroke (Table 3). Cerebral microvascular diseases include lacunar infarction, white matter hyper-intensity lesions, and intracerebral hemorrhage (including microbleeds), which are often observed in the regions perfused by deep perforating arteries. Several previous studies have associated these microvascular lesions with elevations in aortic PWV and $\mathrm{BP}^{133-137)}$. The underlying mechanisms are likely that 1) the small perforating arteries are directly branched from the large cerebral arteries and 2) BP and flow pulsations are prone to deeply transmitting into the cerebral microvasculature on account of its low impedance properties ${ }^{132,138)}$. It is thought that with aortic stiffening, BP pulsation in large arteries becomes greater; thus, higher pulsatile stress is imposed on the fragile microvascular walls, which results in microvascular injury and eventually causes ischemic or hemorrhagic stroke.

In contrast to microvascular stroke, macrovascular stroke usually occurs in the regions perfused by large cortical arteries and could be fatal in some cases. Studies have demonstrated that aortic PWV is an independent predictor of fatal stroke ${ }^{139)}$. The underlying hemodynamic mechanisms linking aortic stiffness to macrovascular stroke may include 1) cerebral 
Table 3. Different characteristics of micro- and macrovascular stroke

\begin{tabular}{lll}
\hline Stroke types & \multicolumn{1}{c}{ Microvascular } & Macrovascular \\
\hline Designations & $\begin{array}{l}\cdot \text { Lacunar infarction } \\
\cdot \text { Hemorrhagic stroke (including microbleeds) }\end{array}$ & $\cdot$ Cortical infarction \\
\hline Main causes & Lipohyalinosis & $\cdot$ Atherosclerosis \\
& & $\cdot$ Thromboembolism \\
\hline Vascular territories & Small deep perforating arteries & Cerebral/carotid/vertebral arteries \\
\hline Association with aortic stiffness & + & + \\
\hline Suggested central hemodynamic mechanisms & $\cdot$ High aortic pressure & $\cdot$ High aortic pressure \\
\hline
\end{tabular}

thromboembolism due to plaque rupture in the carotid/cerebral arteries and 2) cardiogenic embolism due to atrial fibrillation, both of which are triggered by widened central PP and/or enhanced peripheral wave reflection ${ }^{140,141)}$. In addition, another mechanism has recently been proposed: 3) retrograde plaque embolism due to the abovementioned aortic flow reversal ${ }^{129)}$. In particular, the term "retrograde embolism" means that atherosclerotic mobile plaques are detached from the aortic arch or descending aortic walls and then retrogradely delivered through the supra-aortic (i.e., carotid and subclavian) arteries up to cerebral arteries to cause "cryptogenic" stroke. This type of stroke can indeed occur ${ }^{142)}$ because diastolic reverse flow in the descending aorta directly contributes to forward flow into the supra-aortic arteries. In addition, the risk of the retrograde embolism may be heightened by aortic stiffening because the stiffer the aorta is, the greater the aortic flow reversal becomes ${ }^{129)}$. The rationale for this retrograde embolism also includes the facts that 1) cryptogenic stroke can occur without any embolic sources in the heart or ascending aorta and 2) mobile plaques are more often seen in the descending aorta than in the ascending aorta $^{143)}$.

\section{2) $\mathrm{CKD}$}

CKD is defined as the presence of (micro)albuminuria and/or a reduced glomerular filtration rate (GFR). Both albuminuria and GFR reduction are often preceded by aortic stiffening, but they can predict future CVD events independently of each other ${ }^{144)}$. This indicates the existence of at least partially different etiologies underlying these distinct entities. Recent investigation does suggest different mediating influences of central hemodynamic (i.e., BP and flow) abnormalities on these aorto-renal associations.

The kidney has a unique structure and function. The renal arteries branch off from the abdominal aorta into intrarenal smaller arteries, leading to tiny afferent arterioles and fragile glomerular capillaries. Intraglomerular pressure is as high as $60 / 40 \mathrm{mmHg}$ even under normal conditions, reflecting the low impedance properties of the renal vasculature. In case of aortosclerosis, the central PP widens, and then, the high BP pulsation is transmitted down to the glomerular capillaries. This most likely results in intraglomerular hypertension and endothelial injury, leading to albuminuria ${ }^{132}$. In fact, central PP and PWV have been shown to be independent predictors of the urinary albumin/creatinine ratio ${ }^{131,145)}$.

Aortic stiffness is also known to be associated with GFR decline ${ }^{146,147)}$. The GFR decline may result from such glomerular injury, as mentioned above, but another possibility has recently been raised that aortic flow abnormality is a primary cause of renal dysfunction accompanying aortosclerosis. As mentioned earlier, aortic stiffening increases flow reversal in the thoracic descending aorta and thus reduces forward flow toward the suprarenal abdominal aorta ${ }^{129)}$. This reduction in suprarenal aortic flow (also caused by an impaired Windkessel function) could reduce blood inflow into the renal arteries (i.e., renal blood flow) and thereby deteriorate GFR ${ }^{148)}$. This flow mechanism could also explain why renal function decreases with age in the general population (i.e., even in the absence of albuminuria).

\section{3) Heart Disease}

For over a half century, numerous studies have shown an important etiological role of central hemodynamics in cardiac diseases. The details have been extensively reviewed previously ${ }^{43},{ }^{149)}$. In brief, an elevation in central BP, which directly reflects left ventricular afterload, is primarily responsible for left ventricular hypertrophy 150,151$)$, causing various cardiac dysfunctions (e.g., heart failure and arrhythmia). Hastening of exponential decay of central BP during diastole, which is accelerated by aortic stiffening, reduces 
the diastolic inflow from the ascending aorta to the coronary arteries and thereby predisposes hypertensive patients to myocardial ischemia ${ }^{152}$. The risk of myocardial ischemia could be further heightened by the presence of atherosclerotic coronary artery stenosis ${ }^{153)}$ and/or left ventricular hypertrophy with increased oxygen demand ${ }^{154)}$. Obviously, more studies are needed to investigate the crucial link between aortic and coronary pulsatile flow.

\section{Conclusions}

The quantitative assessment of central pulsatile hemodynamics has now been enabled by noninvasive tonometry/ultrasound and pulse waveform analysis. Central hemodynamic indices have some advantages in terms of 1) the technical facility for repeated measurements, 2) the immediate response to antihypertensive treatment, and 3) the predictive ability of therapeutic consequences (e.g., preventive effects on CVD). Recent international guidelines or recommendations for vascular biomarkers have also endorsed their usefulness ${ }^{155,156)}$. In the future, for wider application to clinical practice, further investigation is needed to determine the normal reference values, develop handy apparatuses with high precision and dedicated analytical programs, and verify the epidemiological evidence and mechanistic rationale for general use in CVD risk management.

\section{Conflict of Interest}

The author belonged to an endowment department supported with unrestricted grants from Omron Healthcare and MSD.

\section{References}

1) Hales S: Statistical Esseys: Haemastaticks. History of Medical Series, Hafner Publishing (reproduced 1964), New York, 1733

2) Mahomed FA: The etiology of Bright's disease and the prealbuminuric stage. Med Chir Trans, 1874; 57: $197-$ 228

3) Bramwell JC, Hill AV: Velocity of transmission of the pulse wave. Lancet, 1922; 891-892

4) O'Rourke MF, Taylor MG: Input impedance of the systemic circulation. Circ Res, 1967; 20: 365-380

5) O'Rourke MF: The arterial pulse in health and disease. Am Heart J, 1971; 82: 687-702

6) O'Rourke MF, Avolio AP: Pulsatile flow and pressure in human systemic arteries. Studies in man and in a multibranched model of the human systemic arterial tree. Circ Res, 1980; 46: 363-372

7) Murgo JP, Westerhof N, Giolma JP, Altobelli SA: Aortic input impedance in normal man: relationship to pressure wave forms. Circulation, 1980; 62: 105-116

8) Kelly R, Hayward C, Avolio A, O’Rourke M: Noninvasive determination of age-related changes in the human arterial pulse. Circulation, 1989; 80: 1652-1659

9) Karamanoglu M, O’Rourke MF, Avolio AP, Kelly RP: An analysis of the relationship between central aortic and peripheral upper limb pressure waves in man. Eur Heart J, 1993; 14: 160-167

10) Mancia G, De Backer G, Dominiczak A, Cifkova R, Fagard R, Germano G, Grassi G, Heagerty AM, Kjeldsen SE, Laurent S, Narkiewicz K, Ruilope L, Rynkiewicz A, Schmieder RE, Struijker Boudier HA, et al.: 2007 Guidelines for the management of arterial hypertension: The Task Force for the Management of Arterial Hypertension of the European Society of Hypertension (ESH) and of the European Society of Cardiology (ESC). Eur Heart J, 2007; 28: 1462-1536

11) Avolio AP, Van Bortel LM, Boutouyrie P, Cockcroft JR, McEniery CM, Protogerou AD, Roman MJ, Safar ME, Segers P, Smulyan H: Role of pulse pressure amplification in arterial hypertension: experts' opinion and review of the data. Hypertension, 2009; 54: 375-383

12) Herbert A, Cruickshank JK, Laurent S, Boutouyrie P, Reference Values for Arterial Measurements C: Establishing reference values for central blood pressure and its amplification in a general healthy population and according to cardiovascular risk factors. Eur Heart J, 2014; 35: 3122-3133

13) Mahmud A, Feely J: Spurious systolic hypertension of youth: fit young men with elastic arteries. Am J Hypertens, 2003; 16: 229-232

14) Rowell LB, Brengelmann GL, Blackmon JR, Bruce RA, Murray JA: Disparities between aortic and peripheral pulse pressures induced by upright exercise and vasomotor changes in man. Circulation, 1968; 37: 954-964

15) Hashimoto J: Pulse wave velocity and pulse wave analysis. Curr Rev Clin Pathol, 2013; 151: 27-37 (Japanese)

16) Pressman GL, Newgard PM: A Transducer for the continuous external measurement of arterial blood pressure. IEEE Trans Biomed Eng, 1963; 10: 73-81

17) Drzewiecki GM, Melbin J, Noordergraaf A: Arterial tonometry: review and analysis. J Biomech, 1983; 16: $141-152$

18) Chen CH, Nevo E, Fetics B, Pak PH, Yin FC, Maughan WL, Kass DA: Estimation of central aortic pressure waveform by mathematical transformation of radial tonometry pressure. Validation of generalized transfer function. Circulation, 1997; 95: 1827-1836

19) Chen CH, Ting CT, Nussbacher A, Nevo E, Kass DA, Pak P, Wang SP, Chang MS, Yin FC: Validation of carotid artery tonometry as a means of estimating augmentation index of ascending aortic pressure. Hypertension, 1996; 27: 168-175

20) Pauca AL, Wallenhaupt SL, Kon ND, Tucker WY: Does radial artery pressure accurately reflect aortic pressure? Chest, 1992; 102: 1193-1198

21) Mahieu D, Kips J, Rietzschel ER, De Buyzere ML, Verbeke F, Gillebert TC, De Backer GG, De Bacquer D, Verdonck P, Van Bortel LM, Segers P: Noninvasive assessment of central and peripheral arterial pressure 
(waveforms): implications of calibration methods. J Hypertens, 2010; 28: 300-305

22) Hope SA, Meredith IT, Cameron JD: Arterial transfer functions and the reconstruction of central aortic waveforms: myths, controversies and misconceptions. J Hypertens, 2008; 26: 4-7

23) Westerhof BE, Guelen I, Stok WJ, Lasance HA, Ascoop CA, Wesseling KH, Westerhof N, Bos WJ, Stergiopulos $\mathrm{N}$, Spaan JA: Individualization of transfer function in estimation of central aortic pressure from the peripheral pulse is not required in patients at rest. J Appl Physiol, 2008; 105: 1858-1863

24) Payne RA, Lilitkarntakul P, Dhaun N, Melville V, Asai T, Goddard J, Webb DJ: Renal dysfunction does not affect the peripheral-to-central arterial pressure transfer function. Hypertension, 2010; 56: 1083-1088

25) Sharman JE, Lim R, Qasem AM, Coombes JS, Burgess MI, Franco J, Garrahy P, Wilkinson IB, Marwick TH: Validation of a generalized transfer function to noninvasively derive central blood pressure during exercise. Hypertension, 2006; 47: 1203-1208

26) Pauca AL, O'Rourke MF, Kon ND: Prospective evaluation of a method for estimating ascending aortic pressure from the radial artery pressure waveform. Hypertension, 2001; 38: 932-937

27) Cloud GC, Rajkumar C, Kooner J, Cooke J, Bulpitt CJ: Estimation of central aortic pressure by SphygmoCor requires intra-arterial peripheral pressures. Clin Sci, 2003; 105: 219-225

28) Smulyan H, Siddiqui DS, Carlson RJ, London GM, Safar ME: Clinical utility of aortic pulses and pressures calculated from applanated radial-artery pulses. Hypertension, 2003; 42: 150-155

29) Ding FH, Fan WX, Zhang RY, Zhang Q, Li Y, Wang JG: Validation of the noninvasive assessment of central blood pressure by the SphygmoCor and Omron devices against the invasive catheter measurement. Am J Hypertens, 2011; 24: 1306-1311

30) Wilkinson IB, Fuchs SA, Jansen IM, Spratt JC, Murray GD, Cockcroft JR, Webb DJ: Reproducibility of pulse wave velocity and augmentation index measured by pulse wave analysis. J Hypertens, 1998; 16: 2079-2084

31) Siebenhofer A, Kemp C, Sutton A, Williams B: The reproducibility of central aortic blood pressure measurements in healthy subjects using applanation tonometry and sphygmocardiography. J Hum Hypertens, 1999; 13: 625-629

32) Filipovsky J, Svobodova V, Pecen L: Reproducibility of radial pulse wave analysis in healthy subjects. J Hypertens, 2000; 18: 1033-1040

33) Pauca AL, Kon ND, O'Rourke MF: The second peak of the radial artery pressure wave represents aortic systolic pressure in hypertensive and elderly patients. $\mathrm{Br} \mathrm{J}$ Anaesth, 2004; 92: 651-657

34) Hashimoto J, Watabe D, Hatanaka R, Hanasawa T, Metoki H, Asayama K, Ohkubo T, Totsune K, Imai Y: Enhanced radial late systolic pressure augmentation in hypertensive patients with left ventricular hypertrophy. Am J Hypertens, 2006; 19: 27-32

35) Hickson SS, Butlin M, Mir FA, Graggaber J, Cheriyan J, Khan F, Grace AA, Yasmin, Cockcroft JR, Wilkinson IB,
McEniery CM: The accuracy of central SBP determined from the second systolic peak of the peripheral pressure waveform. J Hypertens, 2009; 27: 1784-1788

36) Takazawa K, Kobayashi H, Kojima I, Aizawa A, Kinoh M, Sugo Y, Shimizu M, Miyawaki Y, Tanaka N, Yamashina A, Avolio A: Estimation of central aortic systolic pressure using late systolic inflection of radial artery pulse and its application to vasodilator therapy. J Hypertens, 2012; 30: 908-916

37) Funada J, Takata $Y$, Hashida $H$, Matsumoto $Y$, Sato $S$, Hiasa G, Inoue K, Higaki J, Okayama H: Dysfunctional central hemodynamic regulation after daily meal intake in metabolic syndrome. Atherosclerosis, 2010; 210: 268273

38) Lowe A, Harrison W, El-Aklouk E, Ruygrok P, AlJumaily AM: Non-invasive model-based estimation of aortic pulse pressure using suprasystolic brachial pressure waveforms. J Biomech, 2009; 42: 2111-2115

39) Horvath IG, Nemeth A, Lenkey Z, Alessandri N, Tufano F, Kis P, Gaszner B, Cziraki A: Invasive validation of a new oscillometric device (Arteriograph) for measuring augmentation index, central blood pressure and aortic pulse wave velocity. J Hypertens, 2010; 28: 2068-2075

40) Ageenkova OA, Purygina MA: Central aortic blood pressure, augmentation index, and reflected wave transit time: reproducibility and repeatability of data obtained by oscillometry. Vasc Health Risk Manag, 2011; 7: 649656

41) Weber $T$, Wassertheurer $S$, Rammer $M$, Maurer E, Hametner B, Mayer CC, Kropf J, Eber B: Validation of a brachial cuff-based method for estimating central systolic blood pressure. Hypertension, 2011; 58: 825-832

42) Williams B, Lacy PS, Yan P, Hwee CN, Liang C, Ting CM: Development and validation of a novel method to derive central aortic systolic pressure from the radial pressure waveform using an $\mathrm{N}$-point moving average method. J Am Coll Cardiol, 2011; 57: 951-961

43) O'Rourke MF, Hashimoto J: Mechanical factors in arterial aging: a clinical perspective. J Am Coll Cardiol, 2007; 50: 1-13

44) Hashimoto J, O'Rourke MF: Physical factors in arterial ageing. In: Oxford Textbook of Geriatric Medicine, ed by Michel JP, Beattie BL, Martin FC, and Walston J, Oxford University Press, London, 2018 (In press)

45) Avolio AP, Deng FQ, Li WQ, Luo YF, Huang ZD, Xing LF, O'Rourke MF: Effects of aging on arterial distensibility in populations with high and low prevalence of hypertension: comparison between urban and rural communities in China. Circulation, 1985; 71: 202-210

46) McEniery CM, Wilkinson IB, Avolio AP: Age, hypertension and arterial function. Clin Exp Pharmacol Physiol, 2007; 34: 665-671

47) McEniery CM, Yasmin, Hall IR, Qasem A, Wilkinson IB, Cockcroft JR: Normal vascular aging: differential effects on wave reflection and aortic pulse wave velocity: the Anglo-Cardiff Collaborative Trial (ACCT). J Am Coll Cardiol, 2005; 46: 1753-1760

48) Namasivayam M, McDonnell BJ, McEniery CM, O'Rourke MF: Does wave reflection dominate agerelated change in aortic blood pressure across the human life span? Hypertension, 2009; 53: 979-985 
49) Mitchell GF, Parise H, Benjamin EJ, Larson MG, Keyes MJ, Vita JA, Vasan RS, Levy D: Changes in arterial stiffness and wave reflection with advancing age in healthy men and women: the Framingham Heart Study. Hypertension, 2004; 43: 1239-1245

50) Namasivayam M, Adji A, O'Rourke MF: Aortic augmentation index and aging: mathematical resolution of a physiological dilemma? Hypertension, 2010; 56: e9-10

51) Hayward CS, Kelly RP: Gender-related differences in the central arterial pressure waveform. J Am Coll Cardiol, 1997; 30: 1863-1871

52) Smulyan H, Marchais SJ, Pannier B, Guerin AP, Safar ME, London GM: Influence of body height on pulsatile arterial hemodynamic data. J Am Coll Cardiol, 1998; 31: 1103-1109

53) Gatzka CD, Kingwell BA, Cameron JD, Berry KL, Liang YL, Dewar EM, Reid CM, Jennings GL, Dart AM: Gender differences in the timing of arterial wave reflection beyond differences in body height. J Hypertens, 2001; 19: 2197-2203

54) Stoner L, Faulkner J, Westrupp N, Lambrick D: Sexual differences in central arterial wave reflection are evident in prepubescent children. J Hypertens, 2015; 33: 304-307

55) Wilkinson IB, MacCallum H, Flint L, Cockcroft JR, Newby DE, Webb DJ: The influence of heart rate on augmentation index and central arterial pressure in humans. J Physiol, 2000; 525 Pt 1: 263-270

56) Williams B, Lacy PS, Thom SM, Cruickshank K, Stanton A, Collier D, Hughes AD, Thurston H, O'Rourke M: Differential impact of blood pressure-lowering drugs on central aortic pressure and clinical outcomes: principal results of the Conduit Artery Function Evaluation (CAFE) study. Circulation, 2006; 113: 1213-1225

57) Mahmud A, Feely J: Effect of smoking on arterial stiffness and pulse pressure amplification. Hypertension, 2003; 41: 183-187

58) Vlachopoulos C, Alexopoulos N, Panagiotakos D, O'Rourke MF, Stefanadis C: Cigar smoking has an acute detrimental effect on arterial stiffness. Am J Hypertens, 2004; 17: 299-303

59) Lemogoum D, Van Bortel L, Leeman M, Degaute JP, van de Borne P: Ethnic differences in arterial stiffness and wave reflections after cigarette smoking. J Hypertens, 2006; 24: 683-689

60) Rehill N, Beck CR, Yeo KR, Yeo WW: The effect of chronic tobacco smoking on arterial stiffness. Br J Clin Pharmacol, 2006; 61: 767-773

61) Mahmud A, Feely J: Divergent effect of acute and chronic alcohol on arterial stiffness. Am J Hypertens, 2002; 15: 240-243

62) van Trijp MJ, Beulens JW, Bos WJ, Uiterwaal CS, Grobbee DE, Hendriks HF, Bots ML: Alcohol consumption and augmentation index in healthy young men: the ARYA study. Am J Hypertens, 2005; 18: 792-796

63) Sierksma A, Lebrun CE, van der Schouw YT, Grobbee DE, Lamberts SW, Hendriks HF, Bots ML: Alcohol consumption in relation to aortic stiffness and aortic wave reflections: a cross-sectional study in healthy postmenopausal women. Arterioscler Thromb Vac Biol, 2004; 24: 342-348

64) Vlachopoulos C, Hirata K, O'Rourke MF: Pressure- altering agents affect central aortic pressures more than is apparent from upper limb measurements in hypertensive patients: the role of arterial wave reflections. Hypertension, 2001; 38: 1456-1460

65) Mahmud A, Feely J: Acute effect of caffeine on arterial stiffness and aortic pressure waveform. Hypertension, 2001; 38: 227-231

66) Vlachopoulos C, Alexopoulos N, Dima I, Aznaouridis K, Andreadou I, Stefanadis C: Acute effect of black and green tea on aortic stiffness and wave reflections. J Am Coll Nutr, 2006; 25: 216-223

67) Vlachopoulos C, Kosmopoulou F, Panagiotakos D, Ioakeimidis N, Alexopoulos N, Pitsavos C, Stefanadis C: Smoking and caffeine have a synergistic detrimental effect on aortic stiffness and wave reflections. J Am Coll Cardiol, 2004; 44: 1911-1917

68) Seals DR, Tanaka H, Clevenger CM, Monahan KD, Reiling MJ, Hiatt WR, Davy KP, DeSouza CA: Blood pressure reductions with exercise and sodium restriction in postmenopausal women with elevated systolic pressure: role of arterial stiffness. J Am Coll Cardiol, 2001; 38: 506-513

69) Gates PE, Tanaka H, Hiatt WR, Seals DR: Dietary sodium restriction rapidly improves large elastic artery compliance in older adults with systolic hypertension. Hypertension, 2004; 44: 35-41

70) Haller MJ, Samyn M, Nichols WW, Brusko T, Wasserfall C, Schwartz RF, Atkinson M, Shuster JJ, Pierce GL, Silverstein JH: Radial artery tonometry demonstrates arterial stiffness in children with type 1 diabetes. Diabetes Care, 2004; 27: 2911-2917

71) Schram MT, Henry RM, van Dijk RA, Kostense PJ, Dekker JM, Nijpels G, Heine RJ, Bouter LM, Westerhof N, Stehouwer CD: Increased central artery stiffness in impaired glucose metabolism and type 2 diabetes: the Hoorn Study. Hypertension, 2004; 43: 176-181

72) Lacy PS, O’Brien DG, Stanley AG, Dewar MM, Swales $\mathrm{PP}, \mathrm{Williams} \mathrm{B}$ : Increased pulse wave velocity is not associated with elevated augmentation index in patients with diabetes. J Hypertens, 2004; 22: 1937-1944

73) Maple-Brown LJ, Piers LS, O’Rourke MF, Celermajer DS, O'Dea K: Central obesity is associated with reduced peripheral wave reflection in Indigenous Australians irrespective of diabetes status. J Hypertens, 2005; 23: 14031407

74) Wilkinson IB, Prasad K, Hall IR, Thomas A, MacCallum H, Webb DJ, Frenneaux MP, Cockcroft JR: Increased central pulse pressure and augmentation index in subjects with hypercholesterolemia. J Am Coll Cardiol, 2002; 39: 1005-1011

75) Saba PS, Roman MJ, Longhini C, Scorzoni D, Pini R, Devereux RB, Ganau A: Carotid intimal-medial thickness and stiffness are not affected by hypercholesterolemia in uncomplicated essential hypertension. Arterioscler Thromb Vac Biol, 1999; 19: 2788-2794

76) Protogerou AD, Blacher J, Aslangul E, Le Jeunne C, Lekakis J, Mavrikakis M, Safar ME: Gender influence on metabolic syndrome's effects on arterial stiffness and pressure wave reflections in treated hypertensive subjects. Atherosclerosis, 2007; 193: 151-158

77) Morigami H, Morioka T, Yamazaki Y, Imamura S, 
Numaguchi R, Asada M, Motoyama K, Mori K, Fukumoto S, Shoji T, Emoto M, Inaba M: Visceral adiposity is preferentially associated with vascular stiffness rather than thickness in men with type 2 diabetes. J Atheroscler Thromb, 2016; 23: 1067-1079

78) Wang J, Wang F, Dong S, Zeng Q, Zhang L: Levels of serum phosphorus and cardiovascular surrogate markers. J Atheroscler Thromb, 2016; 23: 95-104

79) Owen PJ, Rajiv C, Vinereanu D, Mathew T, Fraser AG, Lazarus JH: Subclinical hypothyroidism, arterial stiffness, and myocardial reserve. J Clin Endocrinol Metab, 2006; 91: 2126-2132

80) Smith JC, Page MD, John R, Wheeler MH, Cockcroft JR, Scanlon MF, Davies JS: Augmentation of central arterial pressure in mild primary hyperparathyroidism. J Clin Endocrinol Metab, 2000; 85: 3515-3519

81) Phillips C, Hedner J, Berend N, Grunstein R: Diurnal and obstructive sleep apnea influences on arterial stiffness and central blood pressure in men. Sleep, 2005; 28: 604-609

82) Phillips CL, Yee B, Yang Q, Villaneuva AT, Hedner J, Berend N, Grunstein R: Effects of continuous positive airway pressure treatment and withdrawal in patients with obstructive sleep apnea on arterial stiffness and central BP. Chest, 2008; 134: 94-100

83) Senzaki H, Chen CH, Ishido H, Masutani S, Matsunaga T, Taketazu M, Kobayashi T, Sasaki N, Kyo S, Yokote Y: Arterial hemodynamics in patients after Kawasaki disease. Circulation, 2005; 111: 2119-2125

84) Klocke R, Cockcroft JR, Taylor GJ, Hall IR, Blake DR: Arterial stiffness and central blood pressure, as determined by pulse wave analysis, in rheumatoid arthritis. Ann Rheum Dis, 2003; 62: 414-418

85) Hashimoto J, O'Rourke MF: Inflammation and arterial stiffness in chronic kidney disease: cause or consequence? Am J Hypertens, 2017; 30: 350-352

86) Bartoloni E, Pucci G, Cannarile F, Battista F, Alunno A, Giuliani M, Cafaro G, Gerli R, Schillaci G: Central hemodynamics and arterial stiffness in systemic sclerosis. Hypertension, 2016; 68: 1504-1511

87) Lemogoum D, Van Bortel L, Najem B, Dzudie A, Teutcha C, Madu E, Leeman M, Degaute JP, van de Borne P: Arterial stiffness and wave reflections in patients with sickle cell disease. Hypertension, 2004; 44: 924-929

88) London GM, Blacher J, Pannier B, Guerin AP, Marchais SJ, Safar ME: Arterial wave reflections and survival in end-stage renal failure. Hypertension, 2001; 38: 434-438

89) Safar ME, Blacher J, Pannier B, Guerin AP, Marchais SJ, Guyonvarc'h PM, London GM: Central pulse pressure and mortality in end-stage renal disease. Hypertension, 2002; 39: 735-738

90) Covic A, Mardare N, Gusbeth-Tatomir P, Prisada O, Sascau R, Goldsmith DJ: Arterial wave reflections and mortality in haemodialysis patients - only relevant in elderly, cardiovascularly compromised? Nephrol Dial Transplant, 2006; 21: 2859-2866

91) Briet M, Collin C, Karras A, Laurent S, Bozec E, Jacquot C, Stengel B, Houillier P, Froissart M, Boutouyrie P: Arterial remodeling associates with CKD progression. J Am Soc Nephrol, 2011; 22: 967-974

92) Verbeke F, Marechal C, Van Laecke S, Van Biesen W,
Devuyst O, Van Bortel LM, Jadoul M, Vanholder R: Aortic stiffness and central wave reflections predict outcome in renal transplant recipients. Hypertension, 2011; 58: 833-838

93) Ueda H, Hayashi T, Tsumura K, Yoshimaru K, Nakayama Y, Yoshikawa J: The timing of the reflected wave in the ascending aortic pressure predicts restenosis after coronary stent placement. Hypertens Res, 2004; 27: $535-540$

94) Weber T, Auer J, O’Rourke M F, Kvas E, Lassnig E, Lamm G, Stark N, Rammer M, Eber B: Increased arterial wave reflections predict severe cardiovascular events in patients undergoing percutaneous coronary interventions. Eur Heart J, 2005; 26: 2657-2663

95) Chirinos JA, Zambrano JP, Chakko S, Veerani A, Schob A, Willens HJ, Perez G, Mendez AJ: Aortic pressure augmentation predicts adverse cardiovascular events in patients with established coronary artery disease. Hypertension, 2005; 45: 980-985

96) Jankowski P, Kawecka-Jaszcz K, Czarnecka D, Brzozowska-Kiszka M, Styczkiewicz K, Loster M, KlochBadelek M, Wilinski J, Curylo AM, Dudek D: Pulsatile but not steady component of blood pressure predicts cardiovascular events in coronary patients. Hypertension, 2008; 51: 848-855

97) Weber T, O’Rourke MF, Lassnig E, Porodko M, Ammer M, Rammer M, Eber B: Pulse waveform characteristics predict cardiovascular events and mortality in patients undergoing coronary angiography. J Hypertens, 2010; 28: 797-805

98) Roman MJ, Devereux RB, Kizer JR, Lee ET, Galloway JM, Ali T, Umans JG, Howard BV: Central pressure more strongly relates to vascular disease and outcome than does brachial pressure: the Strong Heart Study. Hypertension, 2007; 50: 197-203

99) Roman MJ, Devereux RB, Kizer JR, Okin PM, Lee ET, Wang W, Umans JG, Calhoun D, Howard BV: High central pulse pressure is independently associated with adverse cardiovascular outcome the strong heart study. J Am Coll Cardiol, 2009; 54: 1730-1734

100) Pini R, Cavallini MC, Palmieri V, Marchionni N, Di Bari M, Devereux RB, Masotti G, Roman MJ: Central but not brachial blood pressure predicts cardiovascular events in an unselected geriatric population: the ICARe Dicomano Study. J Am Coll Cardiol, 2008; 51: 2432-2439

101) Leone N, Ducimetiere P, Gariepy J, Courbon D, Tzourio C, Dartigues JF, Ritchie K, Alperovitch A, Amouyel P, Safar ME, Zureik M: Distension of the carotid artery and risk of coronary events: the three-city study. Arterioscler Thromb Vac Biol, 2008; 28: 1392-1397

102) Benetos A, Thomas F, Joly L, Blacher J, Pannier B, Labat C, Salvi P, Smulyan H, Safar ME: Pulse pressure amplification a mechanical biomarker of cardiovascular risk. J Am Coll Cardiol, 2010; 55: 1032-1037

103) Wang KL, Cheng HM, Chuang SY, Spurgeon HA, Ting CT, Lakatta EG, Yin FC, Chou P, Chen CH: Central or peripheral systolic or pulse pressure: which best relates to target organs and future mortality? J Hypertens, 2009; 27: 461-467

104) Wang KL, Cheng HM, Sung SH, Chuang SY, Li CH, Spurgeon HA, Ting CT, Najjar SS, Lakatta EG, Yin FC, 
Chou P, Chen CH: Wave reflection and arterial stiffness in the prediction of 15-year all-cause and cardiovascular mortalities: a community-based study. Hypertension, 2010; 55: 799-805

105) Huang CM, Wang KL, Cheng HM, Chuang SY, Sung SH, Yu WC, Ting CT, Lakatta EG, Yin FC, Chou P, Chen $\mathrm{CH}$ : Central versus ambulatory blood pressure in the prediction of all-cause and cardiovascular mortalities. J Hypertens, 2011; 29: 454-459

106) Mitchell GF, Hwang SJ, Vasan RS, Larson MG, Pencina MJ, Hamburg NM, Vita JA, Levy D, Benjamin EJ: Arterial stiffness and cardiovascular events: the Framingham Heart Study. Circulation, 2010; 121: 505-511

107) Hashimoto J, Ito S: Central blood pressure and prediction of cardiovascular events. Curr Hypertens Rev, 2012; 8: 108-113

108) McEniery CM, Yasmin, McDonnell B, Munnery M, Wallace SM, Rowe CV, Cockcroft JR, Wilkinson IB: Central pressure: variability and impact of cardiovascular risk factors: the Anglo-Cardiff Collaborative Trial II. Hypertension, 2008; 51: 1476-1482

109) Cheng HM, Chuang SY, Sung SH, Yu WC, Pearson A, Lakatta EG, Pan WH, Chen CH: Derivation and validation of diagnostic thresholds for central blood pressure measurements based on long-term cardiovascular risks. J Am Coll Cardiol, 2013; 62: 1780-1787

110) Kelly RP, Gibbs HH, O’Rourke MF, Daley JE, Mang K, Morgan JJ, Avolio AP: Nitroglycerin has more favourable effects on left ventricular afterload than apparent from measurement of pressure in a peripheral artery. Eur Heart J, 1990; 11: 138-144

111) Morgan T, Lauri J, Bertram D, Anderson A: Effect of different antihypertensive drug classes on central aortic pressure. Am J Hypertens, 2004; 17: 118-123

112) Dahlof B, Sever PS, Poulter NR, Wedel H, Beevers DG, Caulfield M, Collins R, Kjeldsen SE, Kristinsson A, McInnes GT, Mehlsen J, Nieminen M, O’Brien E, Ostergren J: Prevention of cardiovascular events with an antihypertensive regimen of amlodipine adding perindopril as required versus atenolol adding bendroflumethiazide as required, in the Anglo-Scandinavian Cardiac Outcomes Trial-Blood Pressure Lowering Arm (ASCOTBPLA): a multicentre randomised controlled trial. Lancet, 2005; 366: 895-906

113) Boutouyrie P, Achouba A, Trunet P, Laurent S: Amlodipine-valsartan combination decreases central systolic blood pressure more effectively than the amlodipineatenolol combination: the EXPLOR study. Hypertension, 2010; 55: 1314-1322

114) Williams B, Cockcroft JR, Kario K, Zappe DH, Brunel PC, Wang Q, Guo W: Effects of sacubitril/valsartan versus olmesartan on central hemodynamics in the elderly with systolic hypertension: the PARAMETER study. Hypertension, 2017; 69: 411-420

115) Hashimoto J, Imai Y, O’Rourke MF: Indices of pulse wave analysis are better predictors of left ventricular mass reduction than cuff pressure. Am J Hypertens, 2007; 20: 378-384

116) Boutouyrie P, Bussy C, Hayoz D, Hengstler J, Dartois N, Laloux B, Brunner H, Laurent S: Local pulse pressure and regression of arterial wall hypertrophy during long-term antihypertensive treatment. Circulation, 2000; 101: 2601-2606

117) Hashimoto J, Westerhof BE, Westerhof $\mathrm{N}$, Imai $Y$, O'Rourke MF: Different role of wave reflection magnitude and timing on left ventricular mass reduction during antihypertensive treatment. J Hypertens, 2008; 26: 1017-1024

118) Hashimoto J, Ito S: Some mechanical aspects of arterial aging: physiological overview based on pulse wave analysis. Ther Adv Cardiovasc Dis, 2009; 3: 367-378

119) Williams B, Lacy PS, Cruickshank JK, Collier D, Hughes AD, Stanton A, Thom S, Thurston H: Impact of statin therapy on central aortic pressures and hemodynamics: principal results of the Conduit Artery Function Evaluation-Lipid-Lowering Arm (CAFE-LLA) Study. Circulation, 2009; 119: 53-61

120) Kanaki AI, Sarafidis PA, Georgianos PI, Kanavos K, Tziolas IM, Zebekakis PE, Lasaridis AN: Effects of low-dose atorvastatin on arterial stiffness and central aortic pressure augmentation in patients with hypertension and hypercholesterolemia. Am J Hypertens, 2013; 26: 608-616

121) de Boer SA, Heerspink HJ, Juarez Orozco LE, van Roon AM, Kamphuisen PW, Smit AJ, Slart RH, Lefrandt JD, Mulder DJ: Effect of linagliptin on pulse wave velocity in early type 2 diabetes (RELEASE): a randomized, double-blind, controlled 26-week trial. Diabetes Obes Metab, 2017;

122) Sofer E, Boaz M, Matas Z, Mashavi M, Shargorodsky M: Treatment with insulin sensitizer metformin improves arterial properties, metabolic parameters, and liver function in patients with nonalcoholic fatty liver disease: a randomized, placebo-controlled trial. Metabolism, 2011; 60: 1278-1284

123) Agarwal N, Rice SP, Bolusani H, Luzio SD, Dunseath G, Ludgate M, Rees DA: Metformin reduces arterial stiffness and improves endothelial function in young women with polycystic ovary syndrome: a randomized, placebocontrolled, crossover trial. J Clin Endocrinol Metab, 2010; 95: 722-730

124) Park J, Liao P, Sher S, Lyles RH, Deveaux DD, Quyyumi AA: Tetrahydrobiopterin lowers muscle sympathetic nerve activity and improves augmentation index in patients with chronic kidney disease. Am J Physiol Regul Integr Comp Physiol, 2015; 308: R208-218

125) Jain S, Khera R, Corrales-Medina VF, Townsend RR, Chirinos JA: Inflammation and arterial stiffness in humans. Atherosclerosis, 2014; 237: 381-390

126) Vlachopoulos C, Aznaouridis K, Stefanadis C: Prediction of cardiovascular events and all-cause mortality with arterial stiffness: a systematic review and meta-analysis. J Am Coll Cardiol, 2010; 55: 1318-1327

127) Hashimoto J, O'Rourke MF: Is arterial stiffness better than blood pressure in predicting cardiovascular risk? Curr Cardiovasc Risk Rep, 2008; 2: 133-140

128) Mills CJ, Gabe IT, Gault JH, Mason DT, Ross J, Jr., Braunwald E, Shillingford JP: Pressure-flow relationships and vascular impedance in man. Cardiovasc Res, 1970; 4: 405-417

129) Hashimoto J, Ito $S$ : Aortic stiffness determines diastolic blood flow reversal in the descending thoracic aorta: potential implication for retrograde embolic stroke in 
hypertension. Hypertension, 2013; 62: 542-549

130) Hashimoto J, Ito S: Pulse pressure amplification, arterial stiffness, and peripheral wave reflection determine pulsatile flow waveform of the femoral artery. Hypertension, 2010; 56: 926-933

131) Hashimoto J, Ito S: Central pulse pressure and aortic stiffness determine renal hemodynamics: pathophysiological implication for microalbuminuria in hypertension. Hypertension, 2011; 58: 839-846

132) Hashimoto J: Central hemodynamics and target organ damage in hypertension. Tohoku J Exp Med, 2014; 233: $1-8$

133) Hashimoto J, Aikawa T, Imai Y: Large artery stiffening as a link between cerebral lacunar infarction and renal albuminuria. Am J Hypertens, 2008; 21: 1304-1309

134) Henskens LH, Kroon AA, van Oostenbrugge RJ, Gronenschild EH, Fuss-Lejeune MM, Hofman PA, Lodder J, de Leeuw PW: Increased aortic pulse wave velocity is associated with silent cerebral small-vessel disease in hypertensive patients. Hypertension, 2008; 52: 1120-1126

135) Ochi N, Kohara K, Tabara Y, Nagai T, Kido T, Uetani E, Ochi M, Igase M, Miki T: Association of central systolic blood pressure with intracerebral small vessel disease in Japanese. Am J Hypertens, 2010; 23: 889-894

136) Shrestha I, Takahashi T, Nomura E, Ohtsuki T, Ohshita T, Ueno H, Kohriyama T, Matsumoto M: Association between central systolic blood pressure, white matter lesions in cerebral MRI and carotid atherosclerosis. Hypertens Res, 2009; 32: 869-874

137) Mitchell GF, van Buchem MA, Sigurdsson S, Gotal JD, Jonsdottir MK, Kjartansson O, Garcia M, Aspelund T, Harris TB, Gudnason V, Launer LJ: Arterial stiffness, pressure and flow pulsatility and brain structure and function: the Age, Gene/Environment Susceptibility - Reykjavik study. Brain, 2011; 134: 3398-3407

138) O'Rourke MF, Safar ME: Relationship between aortic stiffening and microvascular disease in brain and kidney: cause and logic of therapy. Hypertension, 2005; 46: 200-204

139) Laurent S, Katsahian S, Fassot C, Tropeano AI, Gautier I, Laloux B, Boutouyrie P: Aortic stiffness is an independent predictor of fatal stroke in essential hypertension. Stroke, 2003; 34: 1203-1206

140) Lovett JK, Howard SC, Rothwell PM: Pulse pressure is independently associated with carotid plaque ulceration. J Hypertens, 2003; 21: 1669-1676

141) Shaikh AY, Wang N, Yin $X$, Larson MG, Vasan RS, Hamburg NM, Magnani JW, Ellinor PT, Lubitz SA, Mitchell GF, Benjamin EJ, McManus DD: Relations of arterial stiffness and brachial flow-mediated dilation with new-onset atrial fibrillation: the Framingham Heart Study. Hypertension, 2016; 68: 590-596

142) Harloff A, Strecker C, Dudler P, Nussbaumer A, Frydrychowicz A, Olschewski M, Bock J, Stalder AF, Stroh AL, Weiller C, Hennig J, Markl M: Retrograde embolism from the descending aorta: visualization by multidirectional 3D velocity mapping in cryptogenic stroke. Stroke, 2009; 40: 1505-1508

143) Kronzon I, Tunick PA: Aortic atherosclerotic disease and stroke. Circulation, 2006; 114: 63-75

144) Levin A, Stevens PE: Summary of KDIGO 2012 CKD
Guideline: behind the scenes, need for guidance, and a framework for moving forward. Kidney Int, 2014; 85: 49-61

145) Temmar M, Jankowski P, Peltier M, Mouquet V, Debicka-Dabrowska D, Hamida F, Kawecka-Jaszcz K, Safar ME: Intraaortic pulse pressure amplification in subjects at high coronary risk. Hypertension, 2010; 55: 327-332

146) Ford ML, Tomlinson LA, Chapman TP, Rajkumar C, Holt SG: Aortic stiffness is independently associated with rate of renal function decline in chronic kidney disease stages 3 and 4. Hypertension, 2010; 55: 1110-1115

147) Sedaghat S, Mattace-Raso FU, Hoorn EJ, Uitterlinden AG, Hofman A, Ikram MA, Franco OH, Dehghan A: Arterial stiffness and decline in kidney function. Clin J Am Soc Nephrol, 2015; 10: 2190-2197

148) Hashimoto J, Ito S: Aortic blood flow reversal determines renal function: potential explanation for renal dysfunction caused by aortic stiffening in hypertension. Hypertension, 2015; 66: 61-67

149) Chirinos JA, Segers P: Noninvasive evaluation of left ventricular afterload: part 2: arterial pressure-flow and pressure-volume relations in humans. Hypertension, 2010; 56: 563-570

150) Kollias A, Lagou S, Zeniodi ME, Boubouchairopoulou N, Stergiou GS: Association of central versus brachial blood pressure with target-organ damage: systematic review and meta-analysis. Hypertension, 2016; 67: 183-190

151) Hashimoto J, Nichols WW, O’Rourke MF, Imai Y: Association between wasted pressure effort and left ventricular hypertrophy in hypertension: influence of arterial wave reflection. Am J Hypertens, 2008; 21: 329-333

152) Hashimoto J, Ito $S$ : Central diastolic pressure decay mediates the relationship between aortic stiffness and myocardial viability: potential implications for aortosclerosis-induced myocardial ischemia. J Hypertens, 2017 (In press)

153) Weber T, Auer J, O’Rourke MF, Kvas E, Lassnig E, Berent R, Eber B: Arterial stiffness, wave reflections, and the risk of coronary artery disease. Circulation, 2004; 109: 184-189

154) Hoffman JI, Buckberg GD: The myocardial oxygen supply:demand index revisited. J Am Heart Assoc, 2014; 3: 000285

155) Vlachopoulos C, Xaplanteris P, Aboyans V, Brodmann M, Cifkova R, Cosentino F, De Carlo M, Gallino A, Landmesser U, Laurent S, Lekakis J, Mikhailidis DP, Naka KK, Protogerou AD, Rizzoni D, et al.: The role of vascular biomarkers for primary and secondary prevention. A position paper from the European Society of Cardiology Working Group on peripheral circulation: Endorsed by the Association for Research into Arterial Structure and Physiology (ARTERY) Society. Atherosclerosis, 2015; 241: 507-532

156) Townsend RR, Wilkinson IB, Schiffrin EL, Avolio AP, Chirinos JA, Cockcroft JR, Heffernan KS, Lakatta EG, McEniery CM, Mitchell GF, Najjar SS, Nichols WW, Urbina EM, Weber T: Recommendations for improving and standardizing vascular research on arterial stiffness: a scientific statement from the American Heart Association. Hypertension, 2015; 66: 698-722 